\title{
ECO FRIENDLY SEWERAGE SYSTEM FOR A LOW INCOME COASTAL COMMUNITY
}

\author{
W. N. C. N. Apsara and B. C. Liyanage* \\ Department of Civil Engineering, The Open University of Sri Lanka \\ E-mail-bcliy@ou.ac.lk*, Tel-++ 9411 2881480, Fax- ++ 94112822737
}

\begin{abstract}
The purpose of a sewerage disposal system is to carry human excreta \& urine (Black water) and wastewater (Gray water) back to nature in a proper way without any harm to the environment as well as to human beings. But the implementing and operating costs of the sewerage disposal systems are normally very high which make low income communities unable to access these techniques. The aim of this study was to find a proper sewerage

community consists of 142 families with about 710 people spreading over a $5051 \mathrm{~m}^{2}$ limited area. At first the real situation and the problems prevailing were found through a questionnaire survey considering a proper cross section. Questionnaires were analyzed and evaluated and daily water consumption, sewerage disposal capacities, were found. Finally Eco-sanitation units and simplified sewerage system were selected as the most economical solutions for the problem.
\end{abstract}

Number of Eco-sanitation units required for the said community was 142 . The simplified sewerage system nsidering both self cleansing velocity $(0.5 \mathrm{~m} / \mathrm{s})$ as well as tractive tension $(1 \mathrm{~Pa})$. The results revealed that the best fitted minimum sewer gradient and the minimum sewer diameter were 1 in 208 and 100mm respectively. The collected sewage will be treated in primary and secondary stages in anaerobic digestion units. Three units were provided with each dimension length, width and depth of $6.2 \mathrm{mx} 3 \mathrm{mx} 4 \mathrm{~m}$ respectively and $0.2 \mathrm{~m}$ of free board. Using a lift station a head was added to the effluent to take it from $5 \mathrm{~m}$ below the ground to the ground surface where the Reed bed was provided before it is released to the existing drains that are directed to the sea. Estimated hydraulic retention time of the reed bed is 6.79 hours while dimensions are water depth $=0.6 \mathrm{~m}$ and surface area of the bed $=78 \mathrm{~m}^{2}$. According to the basic cost analysis on two systems Eco-san unit for each house is Rs 47925 . When considering the whole community, the total cost for Eco-san was Rs 6,805,350 while the simplified sewerage system was Rs 2,886,000. However, at the operational stage of simplified sewerage system, with maintenance cost, the total cost was estimated as Rs 16,606,390.00. Therefore, based on the cost the most suitable system for the subjected community is Eco-san. But according to

consumption, improvement of the living standards etc. simplified sewerage system was selected as the best sewerage disposal system to implement at Pitaniya Watta low income community.

Keywords: Sewerage disposal, Low income coastal community, Simplified sewerage system, Eco-san unit.

\section{INTRODUCTION}

The rapid growth of urban population has placed a big pressure on urban infrastructure services such as electricity, water supply, wastewater treatment and solid waste management. As a result, health impacts can be easily identified in low income communities due to improper sanitation. The figure 1 shows how health problems depend on sanitation. In this concept it pays more attention on communal health by removing waste products of the society including human excreta without any hazard to human or nature. This can be done using a proper sanitation system which provides comfort, convenience, and hygiene to consumers with minimal pollution of the environment. 

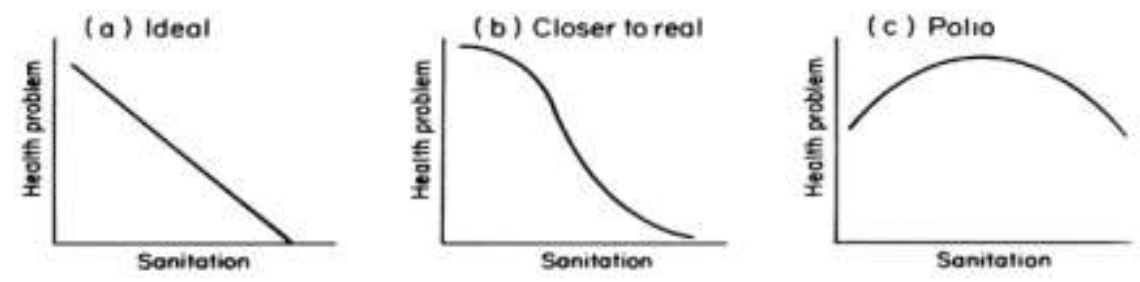

(a) Ideal sanitation (b) Sanitation with small improvements(c) Bad sanitation

Figure 1: Graphs of Health Problems Depend on Sanitation (Pacey 1986)

\subsection{STUDY AREA AND EXISTING SITUATION}

The subjected area is situated by the side of the Colombo Galle coastal high way. The proposed area is $5051 \mathrm{~m}^{2}$ in extent with 142 families and nearly 710 people (personnel interview, Gramasewa Niladari, Koralawela). This is identified as a low-income community. The major income sources of

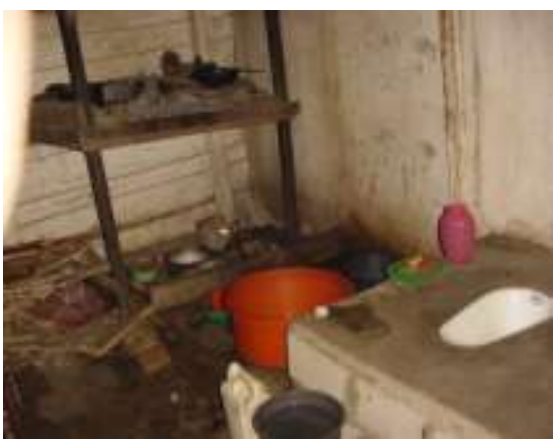

Figure 2: Both cooking and Sanitation in One Little Corner the community are small scale fishery, carpentry and labour work, which provides income in between Rs 2000 - 6000 per day. Due to less money and scarcity of land area the environmental condition has become very poor especially due to improper sanitation. Although, some houses have private toilets, there are no appropriate disposal systems. Even for emptying the pits, there is no access.

The Figure 2 shows the present situation of toilet in a kitchen corner without separation. The people share very limited space for cooking and sanitation. Hence, they use public road drain to dispose excreta. The Figure 3 shows the massive blockage in road drains around the community due to illegal discharge of excreta.

Since there is no waste water disposal system on-site disposal or release to the surface drain is the common practise. When considering the existing situation, this study was aimed to find suitable sewage disposal technologies for low-income and high dense community.

When selecting a technology, affordability of the selected system is also very important for such a low income community. Hence, cost of construction, low maintenance and simple operating system were focused when selecting an appropriate system. Further, the system needs to be suitable to the climate, culture and other environmental and social conditions.

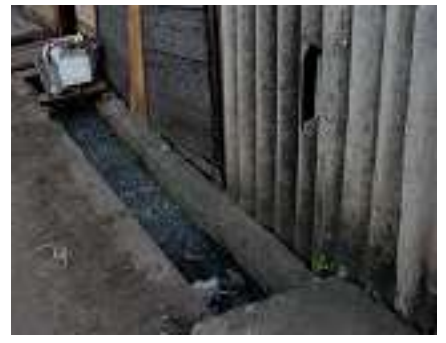

Figure 3: Illegal Excreta Removal to Public

\section{METHODOLOGY}

The questionnaire survey was carried out using a proper cross section among the 48 families. This is well forecast the problem in the proposed area. The questionnaire consist 105 questions with a wide spread to cover areas such as; density of population, living conditions, present sewerage systems, and their desires. The results were analyzed and existent profile on the problem such as income fluctuation, waste disposal methods were obtained and information required for the design such as daily water consumption, peak sewerage flow were gathered. 
Geotechnical data, such as soil formation, ground water table and soil type ie. medium dense sandy soil and dark grayish brown in colour were identified using visual soil classification. Groundwater level was measured using the well adjoining the community land. Measurements were recorded for a week continuously where the major monsoonal rains take place.

A level survey was carried through the points in the community paths, where the future sewer ways have to be located. Future forecast was done on population increment, and design period was considered as 30 years.

\subsection{SYSTEM SELECTION}

In-situ and ex-situ sewerage disposal methods were closely analysed. simple pit latrine, water seal pour-flush latrine, ventilated improved pit latrine (vip latrine), dry compost latrine (eco-san) and septic tank were considered as on site and simplified gravity disposal systems, pumping disposal system (pressure sewer system) were analysed as offsite. Low cost treating methods were also concerned in selection of most suitable system. Based on the preliminary evaluation, eco-san and simplified gravity disposal systems were considered for further evaluation.

\subsection{ECO-SAN SYSTEM}

The Eco-san system (Figure 3) was designed considering two compartments for each unit (Herath, 2001). The compartment capacity pit volume and the pit depth were designed using the standard methods.

\subsection{SIMPLIFIED SEWERAGE SYSTEM}

The system design consists with sewer design (collective sewerage) and treatment plant design (digestion sewage). Sewers were designed based on minimum self cleansing velocity Vsc $=0.5 \mathrm{~m} / \mathrm{s}$ (that prevents the risk of solid deposition and to make flow continuously without any internal blockage) and minimum tractive tension $\tau=1 P a$ (which is exerted by the waste water flow on internal wetted area of boundary walls on the pipes). The most suitable value was selected after comparison. The inverted

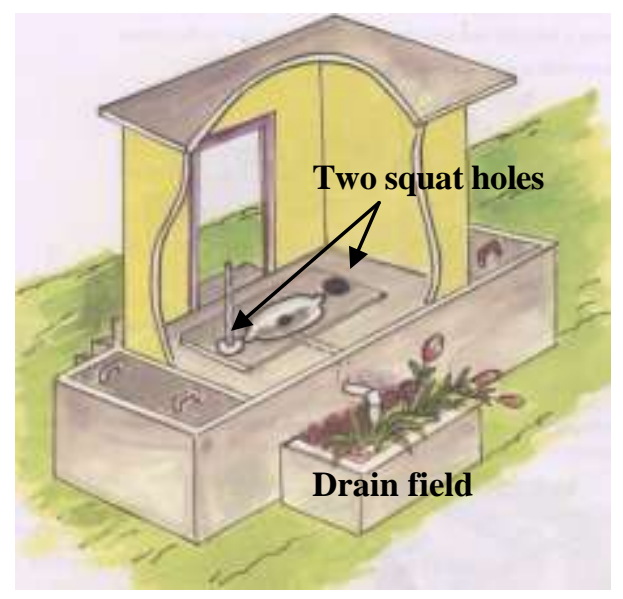

Figure 3: Dry Compost Latrine (Eco-san) levels of each sewer section were found using the Equation 1.

$h_{\text {min }}=C+D$

Where $\mathrm{h}_{\min }=$ invert level $=$ minimum depth permitted from existing ground level to the bottom of the sewer

$\mathrm{C}=$ minimum depth of soil cover, $\mathrm{m}$

$\mathrm{D}=$ sewer diameter, $\mathrm{m}$ (Mara 1996).

In the case of obtaining the sewer gradient and the ground slope five cases were considered.

Case $1 \Rightarrow S\left\langle I_{\text {min }}\right.$ and,$h_{1} \geq h_{\text {min }} ;$ choose,$i=I_{\text {min }}$ and, $h_{2}=h_{1}+\left(I_{\text {min }}-S\right) L$

Case $2 \Rightarrow S=I_{\min }$ and, $h_{1} \geq h_{\min } ;$ choose, $i=I_{\min }$ and,$h_{2}=h_{1}$

Case $3 \Rightarrow S\rangle I_{\min }$ and,$h_{1}=h_{\min } ;$ choose, $i=S$, and,$h_{2}=h_{1}$

Case $4 \Rightarrow S\rangle I_{\min }$ and,$\left.h_{1}\right\rangle h_{\min } ;$ choose, $h_{2}=h_{\min }$ and, $i=S+\left(h_{\min }-h_{1}\right) / L$

Case $5 \Rightarrow S>I_{\min }$ and,$\left.h_{1}\right\rangle h_{\min } ;$ choose,$i=I_{\min }$ and,$h_{2}=h_{1}+\left(I_{\min }-S\right) L$

Where $\mathrm{S}=$ slope of the ground surface

$\mathrm{I}_{\min }=$ minimum sewer gradient obtained in the design

$\mathrm{i}=$ sewer gradient of the considered potion 
$\mathrm{h}_{1}=$ invert depth of the upstream end of the subjected sewer potion

$\mathrm{h}_{2}=$ invert depth of the downstream end of the subjected sewer potion (Mara 1996).

Inverted levels for separate sewer section were considered to maintain the minimum flow. Cleanout units (manholes) were designed at all upstream ends of sewer, major changes in sewer direction, and at major sewer intersections.

In the treatment process the anaerobic digestion unit was selected to carry out primary and secondary treatments. It was decided to install three numbers of units. Improvements were added to increase the digestion process.

A lift station was installed to add required head to sewerage flow to lift it up to the ground level in terms of advanced treatment. The sewage was collected to a sump and lifted by a centrifugal pump. Sump design was done using the detention period. It was designed to have further treatment using a reed bed to improve the quality of the effluent.

\section{RESULTS}

\subsection{QUESTIONNAIRE SURVEY}

The results of this study revealed that per capita water consumption of the subjected area is $110 \mathrm{l} / \mathrm{d}$ and the peak sewage flow is $1.5 \mathrm{l} / \mathrm{s}$. Questionnaire was analyzed to obtain existing sanitation practises, black water disposal and grey water disposal methods as shown in the Figure 4. It was found that $42 \%$ of the community dispose their grey water just into the ground while $29 \%$ dispose those to the adjacent cemetery. $25 \%$ dispose those to road drain, while $4 \%$ drain to open area.
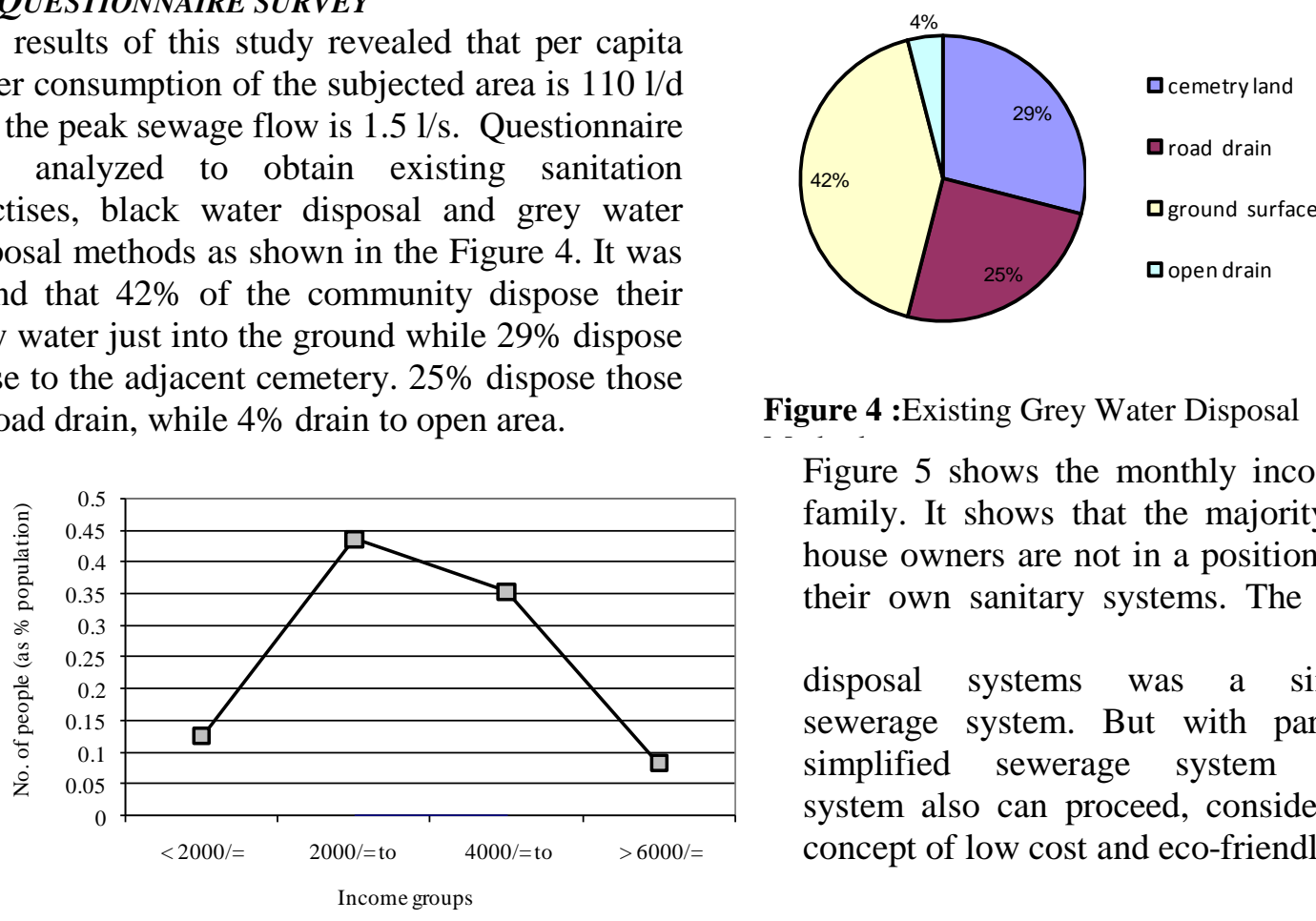

Figure 4 :Existing Grey Water Disposal

Figure 5 shows the monthly income of a family. It shows that the majority of the house owners are not in a position to built their own sanitary systems. The analysis

disposal systems was a simplified sewerage system. But with parallel to simplified sewerage system Eco-san system also can proceed, considering the concept of low cost and eco-friendliness.

Figure 5: Monthly Income of a family

\subsection{DESIGN OF SIMPLIFIED SEWERAGE SYSTEM}

For designing of both systems 30 years design period was considered. Capacity of each compartment of Eco-san is $1 \mathrm{~m} \times 1 \mathrm{~m} \times 0.95 \mathrm{~m}$. In both cases the resultant diameter is $100 \mathrm{~mm}$. Hence, the pipe diameter was selected as $100 \mathrm{~mm}$. The minimum gradient was selected as 1 in 208 which is obtained by the tractive tension design. Therefore, it is $37.5 \%$ less than the $\mathrm{I}_{\min }$ obtained from the self cleansing velocity design. The capacity of, Length, Width, Depth $6.2 \mathrm{~m}, 3 \mathrm{~m}, 4 \mathrm{~m}$ respectively and $0.2 \mathrm{~m}$ of free board.

One sump was installed to collect partially treated sewage to lift to the reed bed. The designed capacity of the sump was; Length, Width, Depth $7.5 \mathrm{~m}, 3.5 \mathrm{~m}, 5 \mathrm{~m}$ respectively and $0.3 \mathrm{~m}$ free board. Two centrifugal pumps to be installed provided a pumping rate each of $2 \mathrm{~kW}$ with the operating time of $53 \mathrm{~min} /$ day. Two pumps were proposed by considering the case of a break down or in any repair. 
Open flow reed bed of 6.79 hours hydraulic retention time has to provide for advanced treatment before discharging into the natural environment.

\subsection{COST ANALYSIS OF ECO-SAN LATRINE AND SIMPLIFIED SEWERAGE SYSTEM}

Construction cost for one unit of eco san is about 47,925.00 rupees. Total estimated cost for 142 households, the cost is about 6,805,350.00 rupees. For Eco-san units, throughout the design period no operation and maintenance cost are needed. Total estimated cost for simplified sewerage system is $16,606,390.00$ rupees inclusive of operational and maintenance cost as well as construction cost.

\section{DISCUSSION}

The proposed Eco-san system consists of basic components that are easy to maintain and therefore has no maintenance cost. The construction of these units is not difficult due to the simple structure. However, if Eco san is selected, it is necessary to introduce a separate system for disposal of wastewater from kitchen, bath and washing (grey water).

The Simplified sewer system is a little complicated and expensive to maintain. For the construction skilled labour as well as supervision is needed. The communicants desire to have a simplified sewerage system. The most significant benefit of this system is that it provides disposal of both black water and grey water and is user friendly too. Existing narrow walkways are ideal to lay collecting sewers. In this area the water table was found to be very low. During the event it records $1.5 \mathrm{~m}$ of water table, which is about $3 \mathrm{~m}$ in dry season. Hence, excavation can proceed up to $5 \mathrm{~m}$, which does not affect dewatering. The average temperature $\left(30^{\circ} \mathrm{C}\right)$ in this area is favourable for reed bed which is employed for advanced treatment of treated effluent. Treated effluent can be released to the sea easily by using the nearby existing drain.

\section{CONCLUSIONS}

Questionnaire survey reveals that community is in utmost need of a disposal system for wastewater. -san is in the second place. The aerial ambient conditions like temperature and sunlight are ideal for the advanced treatment using a Reed bed in the simplified sewerage system and urine disposed plant bed of Ecosan. The very low water table $(>5 \mathrm{~m})$ helps to minimize the excavation cost during the construction of treatment plants. According to the cost analysis the lowest cost is recorded for Eco-san. Due to no maintenance cost of Eco-san, while the simplified sewer system is costly. Hence, when comparing the maintenance, operational and construction costs, the Eco sanitation system is the most economical.

\section{REFERENCES}

Code of practice for the design and construction of septic tanks and associated effluent disposal systems, SLS 745: 2003, Sri Lanka Standards Institution, Colombo 08, Sri Lanka.

Herath N., Latrine Construction, 2001, Helvitas Sri Lanka, Print and Print Graphics (Pvt) Ltd., Colombo 10, Sri Lanka.

Mara D., 1996, Low-Cost Urban Sanitation, John Wiles \& Sons Ltd., West Sussex, England.

Pacey A., 1986, Sanitation in Developing Countries, Page Bros (Norwich)Ltd., Norwich, Britain. 